\title{
COVARIATION BETWEEN VARIABLES IN A \\ MODELLING PROCESS: THE ACODESA \\ (COLLABORATIVE LEARNING, SCIENTIFIC DEBATE AND SELF-REFLECTION) METHOD
}

\author{
Fernando Hitt \& Alejandro S. González-Martín \\ Université du Québec à Montréal - Université de Montréal \\ (1) 514-987-3000 (poste 1428) - (1) 514-343-6111 (poste 8803) \\ (1) 514-987-4186 - (1) 514-343-7286 \\ hitt.fernando@uqam.ca - a.gonzalez-martin@umontreal.ca \\ http://www.er.uqam.ca/nobel/r21245/ \\ http://fse.umontreal.ca/departements/departement-de-didactique/corps- \\ professoral/details/utilisateur/alejandro-gonzalez-martin-44/
}

This work has been funded by Conseil de Recherche en Sciences Humaines du Canada (No. 4102008-1836, CID 130 252).

\begin{abstract}
Semiotic representations have been an important topic of study in mathematics education. Previous research implicitly placed more importance on the development of institutional representations of mathematical concepts in students rather than other types of representations. In the context of an extensive research project, in progress since 2005, related to modelling mathematical situations in Québec secondary schools (grades 8 and 9), we have addressed the problem of constructing a specific mathematical concept: covariation between variables as a prerequisite for the concept of function and its graphical representation. However, our research differs from previous studies as we attempt to take into consideration, in a cultural semiotic perspective, the spontaneous non-institutional representations that students produce when solving a problem situation in mathematics. We report our results with a group of students in grade 9, discussing the evolution of the representations the students produced to solve a problem situation, and the key role that the concept of covariation seems to play in helping students grasp the graphical representation of functions. We also discuss the different stages of the teaching method used, based upon collaborative learning, scientific debate and self-reflection (the ACODESA method of teaching) which aims to help the students acquire a cultural semiotic system.
\end{abstract}

Keywords: covariation between variables, functional representations, cultural semiotic system, ACODESA method, goal-directed thinking, diversified thinking.

\section{Introduction}

This paper discusses a method of teaching (called ACODESA) which fosters a coordinated use of different representations through a modelling process. In 
particular, we focus on a socio cultural milieu and through the use of this method, on students' acquisition of the notion of covariation, as well as the acquisition of the graphical representation of functions. In other words, we aim to facilitate the students' transition from their personal representations to the acquisition and use of institutional mathematical representations through the evolution of Cultural Semiotic Systems (or CSS), as Radford (1998) conceives them (see the Theoretical framework section).

The research presented in this paper is a continuation of an extensive research project that began in 2005. The results of the first stage (see Hitt, 2006; Passaro, 2009) were used as a basis to build upon for the second stage of the research project which takes into account Quebec's new educational programme for grades 9 to 11 (MELS, 2007). In this programme, the process of modelling is introduced in grade 9 and the concept of function appears as a core component of the syllabus.

Our objective in the first stage was to introduce $8^{\text {th }}$ grade students to the notion of covariation, thus introducing the graphic representation of functions before the intensive use of algebraic representations. As such, we developed tasks with the use of manipulative materials (strings, wire, compass and rulers, etc.) in order to experiment the usefulness of these tools in fostering the construction of meaning while solving a mathematical problem. Our results illustrated how students solving the mathematical tasks used embodied actions and produced personal representations in order to understand and to solve the tasks, prior to the use of institutional representations (Hitt, 2006). In the second stage of our research, with $9^{\text {th }}$ grade students, our previous observations led us to distinguish between noninstitutional representations (associated with personal representations) and institutional representations (used by the teacher or usually found in textbooks). (This point is further developed in the Theoretical framework).

In literature, many studies focus on the acquisition of the concept of function. This body of research can be classified according to three different approaches: a focus on static institutional representations, a focus on an integrative approach where mathematical modelisation is fostered (through the notion of covariation) and on dynamic institutional representations.

- Approaches with a focus on static institutional representations

- focusing on the concept of function (e.g. Bloch, 2003; Breidenbach et al., 1992; Carlson, 1998; Harel \& Dubinsky, 1992; Hitt, 1994; Mesa, 2004; Trigueros \& Martínez-Planell, 2010),

- focusing on the concept of covariation between variables (e.g. Carlson 2002; Carlson et al., 2010; Clement, 1989; Monk, 1992; Slavit \& Yeidel, 1999; Thompson, 1994a, 1994b),

- Approaches with a focus on dynamic institutional representations

- focusing on the concept of function (e.g. Falcade et al., 2007; Schwartz \& Dreyfus, 1995; Slavit, 1997).

These studies mostly focus on the observation of students' or teachers' performances related to institutional representations. These works may make it seem that other kinds of representations do not really count in the process of learning the notion of covariation between variables and that of function. 
In an integrative approach to STEM learning, where mathematical modelisation is important it seems that the notion of covariation between variables could help to introduce the graphical representation of functions (e.g. diSessa et al., 1991, González-Martín et al., 2008; Hitt \& Morasse, 2009; Passaro, 2009; Presmeg \& Balderas, 2002). Moreover, during the modelling processes, non-institutional representations emerge spontaneously (diSessa et al., 1991) and these are viewed as possibly assisting the students' to better grasp the notion of covariation and enabling them to better understand the graphical representation of functions. In this sense, we are interested in finding ways to foster the evolution of these noninstitutional representations into the institutional graphic representation of functions.

This paper presents and discusses the ACODESA teaching method (see Hitt, 2007) developed to help students in their transition from their spontaneous, noninstitutional representations for the notion of covariation to the institutional graphical representation of functions. We discuss the usefulness of ACODESA through the analysis of the actions and exchanges of a team of students participating in our experimentation. Our experimentation took place in grade 9 and it followed Québec's new educational programme by competences (MELS, 2007). Our activities, immersed in a modelling process, aim to encourage the emergence of non-institutional representations through the use of manipulative material (artefacts) and focus on the notion of covariation to tackle the graphical representation of functions.

\section{The Québec context: developing competency through the use of problem situations}

The teaching approach by competencies, as proposed by the Québec Ministry of Education (MELS) in 1999, can be viewed as an attempt to tackle the significant problem of knowledge retention (Karsenty, 2003). Among the three competences for secondary mathematics education defined by the Ministry, the first competence is "to solve problem situations" (PS in what follows). As a consequence, the vast majority of the textbooks produced following the recent curricular reform in Québec, start each chapter by presenting a PS. Furthermore, the MELS does not offer a guideline or a specification for the role that problems and exercises should play in the context of the new programme, choosing to focus mainly on the notion of PS. It is our opinion that a proper introduction of mathematical concepts should make use of an adequate and balanced combination of exercises, problems, and PSs, while seeking to clarify their role in both the teaching and learning processes.

Regarding the process of solving exercices, problems, and PSs, we found relevant to introduce the following two new terms: goal-directed thinking and diversified thinking. The first, goal-directed thinking, refers to the students' general processes of solving exercises. This type of thinking emerges from the reading of a statement which encourages the reader to associate the task with an algorithm or method of resolution that applies directly and unconsciously without much reflection. Instead, diversified thinking emerges in the reading of a statement that demands reflection, and an algorithm or method of resolution does not immediately arise, the task is a non-routine task for the solver and possibly requires, from her/him, to build internal representations whose products (external 
representations) promote action to have a different way of looking at the statement.

In the context of the syllabus of Québec, a PS is not usually strictly conceived to have a unique solution, and the student does not know a direct way to resolve it; therefore, diversified thinking is required to generate different ideas to guide the student to one of the possible solutions for the PS. For this reason, we constructed a sequence of activities that exploits the use of PSs at the beginning and gradually moves to more targeted tasks; in this way, our activities can be integrated into the official educational programme of Québec.

\section{Theoretical framework}

\section{The role of functional representations in learning immersed in a}

\section{cultural semiotic system}

Mathematical concepts are accessible through their representations and because a representation is only a partial rendering of the object it represents, a process of conversion among representations is absolutely necessary (Duval, 1993, 1995). But what kind of representations do we need to consider in the construction of mathematical concepts? Only the institutional ones?

Research in the past, from a constructivist perspective, focused mainly on learning approaches based on institutional representations (denoted as IR in what follows) and on the individual's constructions of them. IRs are the kind of representations which are usually accepted and used by the actors of the teaching system: books, computer screens, and teachers.

We believe that the process of learning is not restricted to IRs (diSessa et al., 1991; Font et al., 2010; Hitt, 2003, 2006; Presmeg \& Balderas, 2002). In particular, in the resolution of non-routine tasks requiring diversified thinking, it is possible to produce some spontaneous, non-institutional representations. To take into account the existence and the role of these representations, we introduced the notion of functional representation (denoted as FR in what follows). A FR is a cognitive structure that emerges in the learner when trying to understand and solve a non-routine mathematical task (Hitt, 2003, 2006). It comes to mind before actions are taken, as it controls and organises actions serving as a bridge towards understanding. The external expression of these FRs can be different from an IR, and it allows the learner to better grasp the mathematical task at hand and to act in a structured way while planning a series of actions that lead towards a solution.

We believe that only considering the use of IRs restricts a semiotic system to the classical institutional registers of representations (see e.g. Duval, 1993, 1995; Slavit, 1997). Instead, the consideration of both the institutional and noninstitutional representations and their evolution in a cultural setting (especially in a process of modelling), expands a semiotic system to what we name, in Radford's (1998) sense, a Cultural Semiotic System (CSS):

...signs do not lie randomly in the cultural space of the individuals. Given that culture is not homogeneous, signs are not equally distributed nor used in an indifferent manner. Rather, signs are culturally patterned and socially distributed [...]. They are embodied by what we want to call different cultural semiotic systems... (p. 11) 
In our study, we consider the mathematical classroom as a micro society where a specific way of teaching can encourage the evolution of a CSS. That is, students in a classroom, through a process of social communication, legitimise the signs they use. In our context, students' construction of meaning deals with FRs and IRs and with signs and signifiers evolving in a process of communication (Radford, 1998). The evolution of a CSS, in our context, is related to the transformation and coherent integration of the external representations associated with the FRs through a process of communication in the mathematical classroom.

According to this approach, we have developed a teaching method embedded in a sociocultural setting which fosters the emergence of FRs, diversified thinking and goal-directed thinking. The Methodology section illustrates the basis of this teaching method.

\section{The role of representations in learning based upon a sociocultural semiotic perspective in an expanded activity theory approach}

Radford (1998) coined the notion of CSS taking into account Vygotsky's (1986) and Leontiev's (1981) approaches for learning in relation to activity theory. Leontiev's approach to activity theory is basically related to the articulation between activity and motives, actions and goals, and operations conducted by conditions within a given context. This theory can be viewed as a system to describe social interactions. In Nardi's words (1997):

The object of activity theory is to understand the unity of consciousness and activity. Activity theory incorporates strong notions of intentionality, history, mediation, collaboration and development in constructing consciousness. Activity theorists argue that consciousness is not a set of discrete disembodied cognitive acts (decision making, classification, remembering...) and certainly it is not the brain; rather consciousness is located in everyday practice: you are what you do. And what you do is firmly and inextricably embedded in the social matrix of which every person is an organic part. This social matrix is composed of people and artefacts. (p. 4)

In our case, when students are facing a PS in mathematics (an activity with a motive), actions are taken such as manipulating objects and communicating with others, which leads them to produce and to justify their representations and their gestures in an attempt to understand the PS, to establish goals and to achieve the transformations and conversions among representations (operations) according to the conditions and the context of the PS. We see the students and the teacher as integrating a community, the mathematical classroom; in particular, we are interested in the students' actions and artefact-mediated aspects of their activity involved within a process of communication with others to solve a mathematical task (see ACODESA method of teaching in the Methodology). Due to this, it seems that Engeström's (1999) expanded model of the activity theory related to our classroom community and to our approach of teaching is more suitable to analyze the evolution of a CSS (see Figure 1 in the Methodology), given the wide range of elements interacting in our teaching methodology (e.g., individual work, teamwork, scientific debate, division of labor, artefacts, signs, and conventions of social collaboration). 


\section{Research questions}

We are interested in studying the evolution of personal representations related to the FRs linked to the notion of covariation between variables to produce the IRs related to the graphical representation of functions. For this reason, in this paper, we seek to answer the following two questions:

- To what extend does the ACODESA methodology (based upon a modelling process and the development of a cultural milieu) encourage the evolution of FRs related to the covariation between variables and their products, leading to IRs related to the graphical representation of functions among $9^{\text {th }}$ grade students working on a PS?

- How do students' representations evolve in this context?

In order to address these two questions, we chose to analyse a case study. We analyse the interactions of a particular team of students participating in a normal mathematical class using our teaching methodology, and their interactions with the whole class, including the subsequent debate and the work that they produced at the end of the activity. In the next section, we describe our methodology, the main principles of ACODESA and the activities we used.

\section{Methodology}

Interested in the evolution of a CSS in the mathematics classroom, with FRs at the core of this study, and considering the IRs as a goal, we implemented a method of teaching which we have used in both stages of our research project (see Introduction). This method is a well-articulated combination of collaborative learning (Davidson, 1998), scientific debate (Alibert \& Thomas, 1991; Legrand, 2001), and self-reflection (Hadamard, 1945/1975). This method of teaching is named ACODESA, which in French stands for "collaborative learning, scientific debate and self-reflection", and it is in continuous process of development and refinement (see Hitt, 2007).

ACODESA gives great importance to the evolution of representations in a process of resolution of PSs, to introduce mathematical concepts in the classroom and to foster the development of a diversified thinking in the students, stimulating the emergence of FRs, and goal-directed thinking to promote an evolution of the external representations associated to the FRs. During the resolution of the PS, the teacher is not supposed to provide a solution or to give hints which may lead to one; her/his role is rather to observe the students' individual work, to support a rich exchange of ideas within the sociocultural communication process, and to encourage self-reflexion before the institutionalization of knowledge. This way, the students' work, which usually includes the use of FRs and their external representations during the first stage, gradually evolves during the process of communication. For these reasons, ACODESA integrates both the individual and the socio-cultural settings (the former immersed in the latter) to assist knowledge development. We distinguish 5 different stages in ACODESA:

- Individual work: the students, facing a non-routine task, construct FRs and produce external representations (mostly verbal and diagrams);

- Teamwork: students work in teams on the same task. During this phase, 
refinement of external representations linked to FRs occurs due to processes of argumentation and validation;

- Debate (eventually a scientific debate): during this stage, the entire class discusses different forms of representations to solve the task at hand. The refinement of representations continues during this stage and the role of the teacher should promote an improvement of the students' argumentations. At the end of this stage, the teacher collects all the students' productions;

- Self-reflection (individual work in a process of reconstruction): at this stage, new hand-outs of the same activity are given to the students to work individually at home. This stage allows the students to reconstruct individually what was made in groups, reinforcing the stability of knowledge;

- Institutionalization process: the teacher introduces the topic taking into account the students' results and using the IRs.

As we said before, one of the main contributions of ACODESA is related to the importance given to individual work immersed in a sociocultural learning process. A classical approach is to ask students to work in teams and a general discussion follows. However, due to the fact that consensus is usually ephemeral in the mathematics classroom (Thompson, 2002), some students may revert back to their initial position. Therefore, we propose to collect all the students' productions after the teamwork and the debate stages, asking them later to engage in a process of reconstruction individually, known as a self-reflection. This gives the students the opportunity to incubate and to reconstruct their ideas (which is an important process of the mathematical work, as some mathematicians proclaim, see e.g. Hadamard, 1945/1975). From our theoretical perspective, ACODESA takes into account the fact that a PS triggers diversified thinking, whereas the work within the teams trying to convince teammates should generate goal-directed thinking, in the same way that the debate with the whole class does when trying to "prove" one group's mathematical claims (Hitt, 2007). The process of reconstruction through individual work at home also intends to generate goal-directed thinking. Finally, at the end of the activities, the teacher can initiate the institutionalisation process of teaching.

Figure 1 (left) summarizes how the different stages of ACODESA are combined and Figure 1 (right) illustrates our interpretation of Engeström's model (1987, p. 78), showing how we see the relations between the different elements present in the community: the subjects, the artefacts, the rules, the community, and the object of learning. For example, division of labour is related to several stages of our method of teaching. Those relations explicit in Figure 1 (right) must be taken into account when explaining the students' cognitive constructions. Sense meaning is a cognitive product that is immersed in a cyclic process, related to the sequence of the activities promoting an evolution of a CSS in the mathematical classroom. 

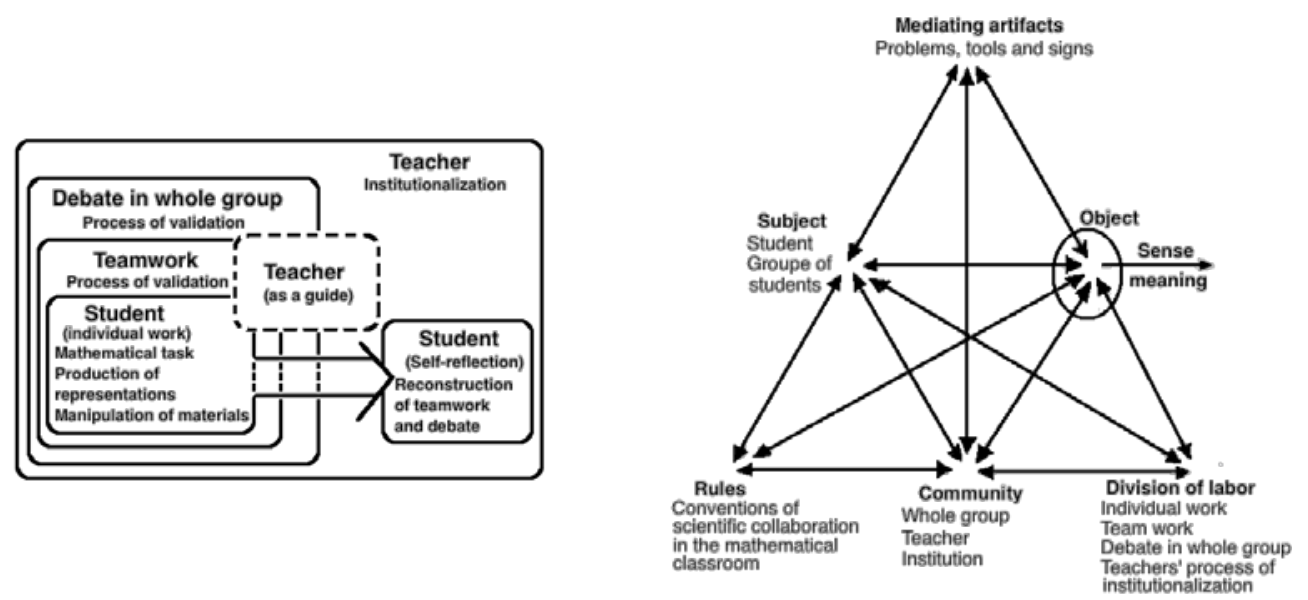

Figure 1. Organisation of the different stages of ACODESA and an interpretation of Engeström's model about relations in a classroom community.

To achieve our objectives, we designed a set of five mathematical activities instead of a single activity (as, for instance, in Artigue, 2002), conceived as a block or a chain of mathematical tasks (see Glaeser, 1999, for recommendations about enchaining activities) over a long-term period of time to promote an evolution of sense meaning in relation to each activity (see Figure 1, right), consolidating at the end of the teaching process the cognitive construction. We experimented with two groups of participants of 24 and 36 pupils, respectively. These pupils were 14-15 year old high school students in grade 9. The main goal of our experimentation was to help the pupils grasp graphical and algebraic representations of functions, through the notion of covariation between variables in a modelling process. In our experimentation, we elaborated the five activities ${ }^{1}$ as explained above to foster both the emergence of FRs and their associated external representations. Verbal or visual representations with drawings are two of the possible external forms that enable the students to share and to compare their FRs.

Figure 2 illustrates (left) the sequence of activities, as well as the types of representation targeted with each one; the diagram (right) stresses the articulations among representations, leaving the algebraic representations at the end of the process. It is important to note that this implementation of ACODESA was done with the agreement of the teacher with whom we constructed the different activities, as he knew better the students and their interests, and the contents he had to cover during the lessons.

\footnotetext{
${ }^{1}$ Some of these activities were inspired by preliminary versions constructed in an undergraduate course by C. Janvier, B. Janvier and L. Charbonneau: Didactique de la variable et des fonctions, at Université du Québec à Montréal. Passaro added some modifications in her Masters' study of the activity The hiker (see Passaro, 2009).
} 


\begin{tabular}{|c|c|c|c|c|}
\hline $\begin{array}{c}\text { PS } \backslash \text { Representation } \\
\text { expected }\end{array}$ & $\begin{array}{c}\text { Drawing } \\
\text { or } \\
\text { diagram }\end{array}$ & Verbal & Graphic & Algebraic \\
\hline The Photographer & $\mathrm{X}$ & $\mathrm{X}$ & & \\
\hline The Hiker & $\bar{X}$ & $\mathrm{X}$ & $X$ & \\
\hline The Jacuzzi & $\mathrm{X}$ & $\bar{X}$ & $\mathrm{X}$ & $\mathrm{X}$ \\
\hline The Squares & $\mathrm{X}$ & $\mathrm{X}$ & $\mathrm{X}$ & $\mathrm{X}$ \\
\hline The Shadows & $\mathrm{X}$ & $\mathrm{X}$ & $\mathrm{X}$ & $\mathrm{X}$ \\
\hline
\end{tabular}

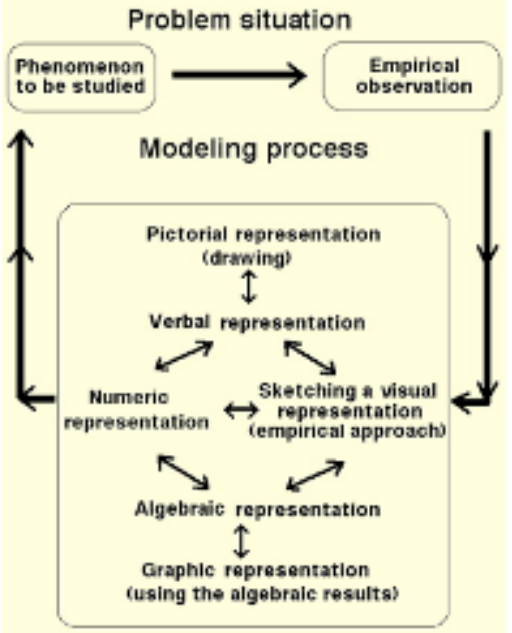

Figure 2. Activities and types of representations expected and principles for the design of the activities

For this implementation of ACODESA, the students worked on these five activities during thirteen lessons (each lesson lasting seventy minutes), covering the contents the teacher needed to cover for the introduction of functions. All the lessons were videotaped with two cameras. Due to space limitations, we only discuss our results with one of the two groups (24 students - this group was previously labelled by the teacher as the weak one). In particular, we focus on the exchanges of a team of students and some interactions with their class. It is important to note here that, in spite of the length of the implementation of the activities, the teacher could introduce all the elements he wanted to introduce during this chapter. Some time usually used to work on exercises and routine problems was replaced by substantial time to work on covariation, and by the end of the semester, the teacher had covered all the contents he needed to cover. However, Passaro (2009) used one of the activities in grade 8 (The hiker) to introduce the idea of graphic representation and covariation. In our case, the whole sequence was conceived to be able to gradually introduce covariation as a prerequisite of the concept of function including an algebraic approach, and to help students shift from their FRs to the IRs, with substantial time for discussion and consolidation of learning.

The following section analyses the students' actions during some key excerpts of the second activity, The hiker, paying special attention to the actions that the students performed during their teamwork sessions and the debate with the whole group. We discuss how the activity promotes the development of the notion of covariation between variables. Also, in the analysis of the key excerpts we illustrate some of the key aspects of how ACODESA works.

\section{Collaborative productions in a sociocultural learning setting}

The experimentation began with The photographer. This PS was designed as an introductory activity to facilitate the students' entry into the new way of functioning of our methodological approach. As expected, the institutional graphic representation did not appear immediately in the work of the students, but products of FRs did appear in this activity. Individual productions from FRs and an evolution of these FRs are presented in Hitt \& Morasse (2009). 
As previously mentioned, this paper focuses on the second activity, The hiker. We analyse the students' work during this activity while paying particular attention to the different stages and aspects of ACODESA in relation with our theoretical approach. The hiker is the core PS of our block of activities. The different tasks of the activity (see Figure 3) are designed to foster the construction of the graphical representation of functions related to the path chosen for this activity. In this class (we stress the fact that it was labelled by the teacher as a weak group) a very interesting debate took place among the students, leading them to produce some original work that was unexpected by both the teacher and the researchers.

Page 1 (general information).

Page 2

A hiker undertakes a long excursion in a forest. He follows a closed path, which allows him to return to his starting point at the end of the excursion. During the walk, the track never passes by the same point twice, in essence, completing only one circuit. An aid station is located within the area surrounded by the track. A flagpole makes it possible for the hiker to locate the site of the aid station wherever he is on the track.

Trace a track of your choice and place the aid station inside the track.

Page 3

The distance between the hiker and the aid station varies according to the location of the hiker on the track. Describe this variation.

Page 4

Find a new way to present the phenomenon described on page 3, excluding the drawing of the track appearing there.

Page 5

By using the answer to the preceding question (page four), describe in your own words how the distance between the hiker and the aid station varies depending on the place where the hiker is situated on the track.

Pages 6 to 10 (reverse process)

In summary, the activity asked the students, working in teams, to place the flagpole in a different place, to sketch a graphic representation of the new situation, and to show only the graph to the rest of the class asking them to guess where the flagpole was situated.

Figure 3. The hiker

In this activity the production of algebraic representations is not targeted (see Figure 2). Instead, the activity fosters the emergence of diversified thinking (first 5 pages), and that is precisely the reason why the students are allowed to choose their own path.

The question on page 3 requires the students to use their own, personal representations in order to model the situation, encouraging them to start achieving an understanding of how the following two magnitudes vary: the distance walked and the distance to the flagpole. The question on page 4 attempts to lead the students into a new way to represent the situation, eventually heading towards the institutional graphic representation of a function.

\section{Episode 1: Individual work}

The students were given time (a few minutes) to think of a track for the activity, and after this a general discussion was held with the whole class with the goal of choosing a common particular track (all the students would work on the same 
track). The students arrived at a consensus, choosing a squared-shaped path with the flagpole situated in the middle. In the previous experimentations in grade 8 , students' choice of a track was less geometric than in grade 9 (Passaro, 2009).

After the first analysis of the videos, we chose to focus on the work of a particular team of students due to the rich interactions among them and because this group later made a presentation to the whole class that triggered a debate. This team was formed by two girls (Agnes and Betty) and two boys (Charlie and Damien). Their individual work, produced in the first stage of the PS, prior to the choosing of the common path by the whole class, is presented in Figure 4.

\begin{tabular}{|c|c|c|c|}
\hline$(10 \square$ & & & \\
\hline Agnes & Betty & Charlie & Damien \\
\hline
\end{tabular}

Figure 4. Individual work of Agnes, Betty, Charlie and Damien

Agnes's and Charlie's individual work is based on regular geometric figures and both decided to represent the flagpole with just one point. Betty's productions combine regular and non-regular geometric shapes. Damien's proposal is a nongeometric, more detailed representation, showing a valley and also sketching some ideas about the variables (distance from the hiker to the flagpole). The productions of these four students seem to indicate that not all the students had immediately at their disposal IRs to tackle the activity about covariation between variables, and even the students who used IRs did not know what to do with them. We can also say that the PS fostered some diversified thinking in some students and led them to produce FRs.

When the whole class chose the square path for this PS, Charlie's individual work shows he was thinking about the variable "angle". Once the group work started, the first exchanges with his teammates made him realise that the PS was making reference to the variables "distance travelled by the hiker" and "distance to the flagpole" (see his marks around the square in Figure 5) and as a result, he chose to cross out his comments about the angles. From this point, the students were asked to use red ink, allowing the researchers to distinguish in the sheets between individual and teamwork. Charlie crossed out what he had written about the angle as a variable and added arrows to show when the distance of the hiker to the flagpole was increasing or decreasing.

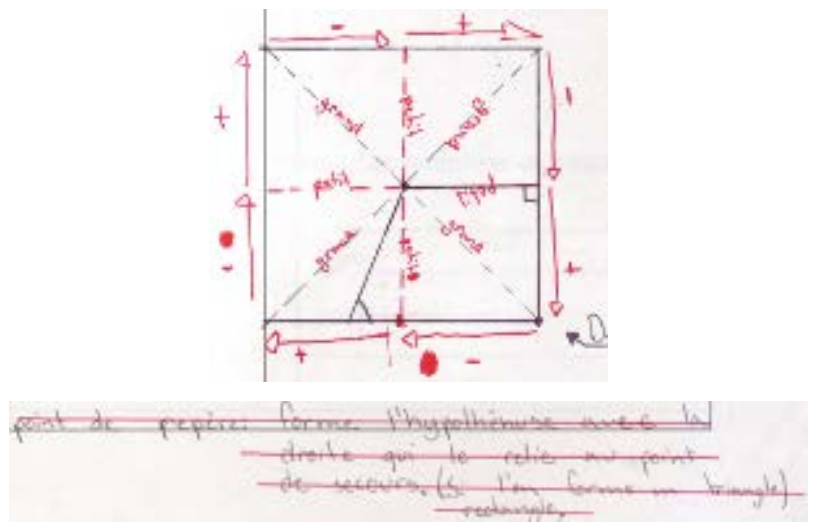

Figure 5. Individual work made by Charlie before and during teamwork. 
As we see, the immersion of the individual work in the sociocultural environment provided by the teamwork helped the students to start better grasping the PS and to refine their representations. Betty's and Damien's productions also started to evolve. When they arrived at page 4 they got stuck about finding a new representation.

\section{Episode 2: Teamwork, from diversified thinking to goal-directed thinking}

In the following section, we describe the students' actions, based on Engeström's model $(1987,1999)$ of the class seen as a community and in relation to Radford's notion of CSS in a sociocultural setting of learning. With reference to the question on page 4 (see Figure 3), the students were asked to create a new representation for the phenomenon described in the activity in order to continue triggering diversified thinking that had already begun with the selection of the path.

Initially, on page 4, the students had difficulty identifying where to begin. As a result, the teacher suggested that they make use of the manipulative material, then all the students manipulated a piece of flexible wire (mediational artefact) and bended it to recreate the squared track. Two teams also used string and cut it into pieces in order to represent the distance between the hiker and the flagpole at different points of the track. They chose the mid points of the side of the square and the corners for this representation.

Following this suggestion to use physical material, the two girls started manipulating the material (meditational artefacts) while Charlie took notes of their discussion (subjects, rules and division of labor), however Damien was not actively participating. After a moment of manipulation, Agnes realized that the use of the string did not help her very much, since it would not remain in a fixed position when manipulating the wire, it would only hang loosely instead. She was disappointed about this, which led her to abandon the use of the material. Betty took the initiative to replace the string with some sticks (as in Figure 6, left). When changing from the PS representation on paper to the physical situation with wire and sticks, sign and signified were embodied by this action, thus creating a new representation of the PS with the physical object. Consequently, a new sign and signified were the result of this activity. At this stage, both girls thought they had finished with the task.
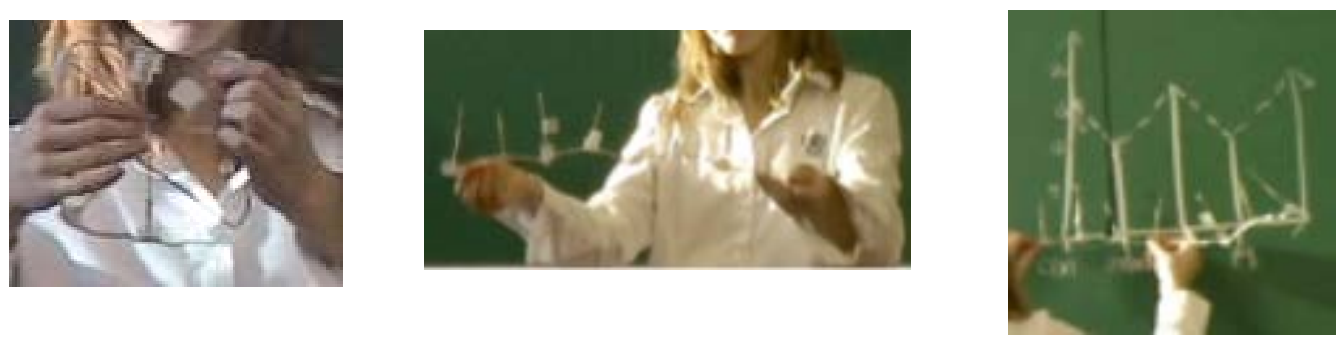

Figure 6. Agnes manipulating the materials in front of the whole class and Damien's graphical representation related to The hiker.

At this stage in ACODESA, the teacher guides the students not by giving answers, but by promoting reflection. While the task initially seemed difficult when approached from the perspective of individual work, working as a team the 
students were able to get a better grasp of the situation. However, they were limited to the paper and pencil environment. The manipulation of the physical material provoked a shift, in a diversified thinking perspective, moving the team from one environment to another one to finally uncover a new representation.

The teacher arrived at this moment and asked the team whether the vision of the unwound wire (see Figure 6, middle) with the sticks reminded them of something. Charlie, who was in charge of writing (division of labor), said that what they had found was related to a coordinate plane and a graph (new sign and signified were created showing an evolution of a CSS and sense meaning). We see here a shift from the external representation of a FR to the identification with an IR (the Cartesian plane - the graphical representation of linear functions had been presented to the students during their previous year). Charlie added that the horizontal line (the unwound wire) represented the distance of the hiker on the track, and that the sticks represented the distance from the hiker at different points to the flagpole, showing a very good level of understanding of the correlation between the two variables, and making a connection to the notion of function, helped by the representation offered by the manipulative material. Indeed, moving his hand (gestures as mediational artefacts), he outlined a smooth curve, but when the teacher asked him to repeat, Charlie moved his hand to outline a curve made by straight segments (maybe thinking he had said something wrong). After a first moment of surprise (Agnes reacted: "What? A coordinate plane?”, and Betty said: "He is crazy! He is crazy!"), the whole team began a process of goal-directed thinking, trying to represent what Charlie had said and did (retaining the idea about the straight segments). We see here that the activity, and the exchanges among the students, seemed to foster a shift from diversified thinking and FR to the gradual development of a goal-directed thinking. The study of the covariation between two magnitudes, and the use of materials (artefacts), seems to have helped the students to start thinking about the graphical representation of functions, which did not occur spontaneously. The lesson finished at that moment, and the fact that the students could relate to their physical construction to explain the situation, making a connection with knowledge from the year before makes us believe that a psychological tool (semiotic mediation) was constructed (Bartolini Bussi, 2010; Rabardel, 1995; Radford, 1998).

In this excerpt, we can interpret that the sign and signified embodied by the activity were different in the case of Betty and Agnes, but the girls induced, indirectly, a different reflection on Charlie. His intervention, on the other hand, provoked a cognitive change in his team members (as we show in the next episode), stimulating sense meaning in the team, and provoking an evolution of the observable products of their FRs. At this stage, the team arrived at a consensus, and supposedly to a similar meaning in an evolution of the CSS.

\section{Episode 3: A scientific debate}

Two days later, during the next period, Damien (who had not shown active participation in the previous sessions), without exchanging with his teammates, drew a graph on the blackboard, using straight dotted lines. After this intervention, Agnes begun to show to the rest of the class the physical object constructed by the team (see Figure 6) to join the edges, as a shift from a discrete physical representation (more attached to the notion of covariation and to FRs) to a continuous representation of the situation (more attached to the notion of function and to the use of the graphical IR). 
The teacher asked the members of the team about the dotted lines they had used to join the edges of the vertical lines (Figure 6 - right) and whether these edges should be joined with straight lines or with another kind of curve. The students in the class, in general, said that a continuous curve is right, with arguments like: "Yeah, because there is an infinite number of [vertical] lines." It seems that Agnes's presentation to her classmates with the material, the physical objects, promoted a mediation of an abstract idea of infinite values of the independent and dependent variables, giving a continuous and dynamic idea of the situation. Indeed, the comments about the "infinite number of [vertical] lines", had an effect on Damien, who changed the dotted lines on the blackboard by solid lines. This presentation by the team and the willingness to join the edges triggered another element of the ACODESA methodology that we, as researchers, were truly waiting for: a real scientific debate (as a social interaction and evolution of a $C S S$ ). Some students disagreed with the first suggestion of joining the edges with straight lines. Erick, a student of another team, suggested a smooth representation of a curve (see Figure 7, left) and immediately Frida disagreed and drew a circle inscribed in a square (see Figure 7, middle), but she was interrupted by Betty, who intervened to say that the curve suggested by Erick actually corresponded to a track with smooth edges and not to a square path (see Figure 7, right). We can see Betty's evolution during this activity, from her initial struggle, to the production of external representations linked to FRs and the use of the materials, to this particular intervention, where she seems to be coordinating different representations for the same situation. However, some pupils did not understand Betty's reasoning and still believed that the right answer was the representation of the smooth curve, while others believed that the right representation was the one with the straight segments.
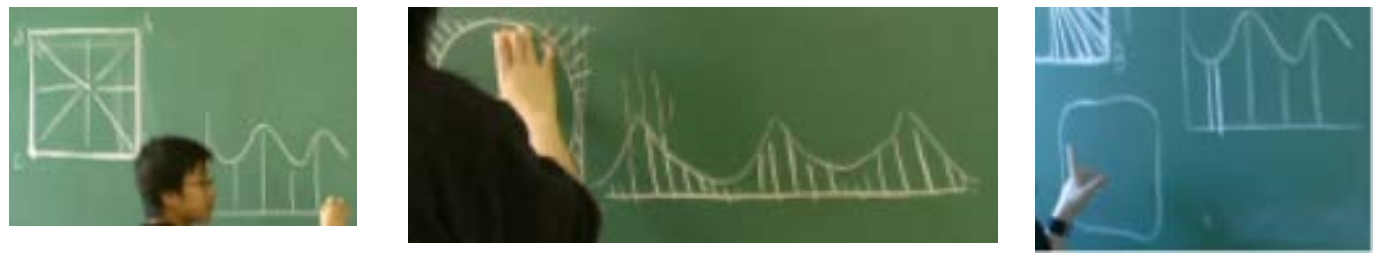

Figure 7. Proposals in a sociocultural process of validation

At this point, Frida, who had been interrupted, said she disagreed with the two given propositions and developed her idea. She drew some segments from the circumference to the borders of the square (her construction was a mental construction, using imaginary sticks). Then, she unwound the imaginary square and imaginary pieces of sticks to obtain a graphic representation of the situation (see Figure 7, middle). The teacher asked about what happens with the measure of the radius of the circle. This interrogation drew her attention to the fact that her graph only represented the distance from the circumference to the square, but not the distance from the centre of the circle to the square. Frida's responded that the form of the curve is the same but translated in vertical direction about the radius of the circle.

Consequently, we can confirm that Frida, in a social interaction, could overcome the blockage imposed by the initial representation on paper of the PS. The mediated role of the wire and sticks and the social interaction assisted her in achieving an abstraction of the situation, shifting from natural (elementary) ideas 
about the situation to a cultural (higher) mental function. The representation of Frida's classmates and the activity embodying sign and signified influenced her and led her to discover a better representation of the PS. With her construction, she was showing sense meaning and finding a new way to represent the situation, which was very close to the graphical representation between variables. We can also conclude that the social interactions considered in the development of ACODESA encouraged an evolution of a CSS (indeed Frida, in the previous lesson, was as baffled as most of her classmates). At this point, covariation between variables was interpreted in a graphical representation. However, the class still needed to address the problem of finding a way to validate which representation, if any, could better represent the phenomenon.

Faced with the three propositions for the graph (Figure 7), the students began excitedly to give their opinion at the same time, so the teacher interrupted the discussion asking them to go back to the work in teams to validate a choice. The students freely went back to the paper and pencil environment putting back the physical material (wire). Several students in each team decided to insert more points on the track and to use a compass (mediational artefact) to measure the distances and preserve them in the graph. As such, they could produce a more accurate graph (see Figure 8), allowing them to follow with Frida's suggestion for the correct form of the curve (Figure 7, middle).
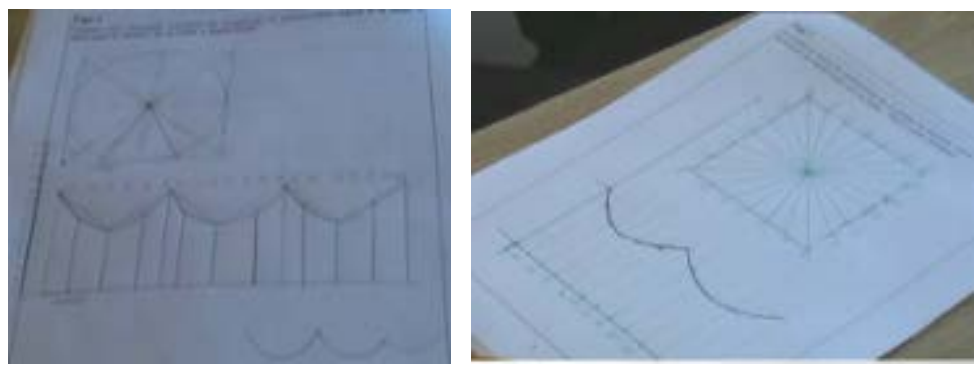

Figure 8. Testing a new conjecture.

This part of the activity allowed the students to embody sign and signified in a dynamic process. Through the evolution of a CSS, the class arrived at a consensus, thus enabling the students to approach the graphical IR of functions from a qualitative process based on the covariation between variables. It is important to add that the pupils had not received any previous instruction about what a mathematical proof was. However, in this case, the use of materials as mediational artefacts and argumentation as semiotic mediation (Bartolini Bussi, 2010; Falcade et al., 2007) were required to validate the students' proposals and to arrive at a consensus.

In the following session, in order to foster an articulation among the different representations, the pupils were asked to perform the reverse process (second part of the activity, see Figure 3, pages 6 to 10 of the sheets). Keeping the same track and choosing a new emplacement for the flagpole, the students were asked to sketch the corresponding graph and to show this sketch to the other teams, but they were to keep the new position of the flagpole a secret. Students performed well at this task, revealing an appropriation of the notion of covariation between variables and its graphic representation (see Figure 9). At this phase, we can confirm that the students, in a social interaction, arrived at the corresponding institutional graphic representation (as planed in the experimentation), which is the one the teacher could use when teaching the topic of functions. 

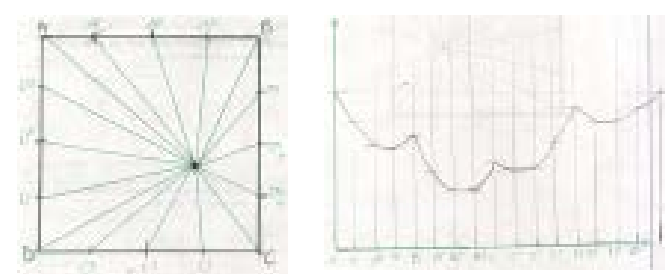

Figure 9. Changing the flagpole and the corresponding graphic (work made by the same team).

\section{Episode 5. Self-reflection (Individual work at home)}

Once the teacher collected all the sheets the students had used to work on during the activity, he assigned the same task as individual work for the students to reconstruct at home. All the students were able to properly solve the activity The hiker individually. We believe that our results indicate that there was an assimilation of the issues discussed in the class during the scientific debate, which were integrated to the students' productions. Indeed, some students incorporated in their work Frida's idea of using a circle (see Figure 10).

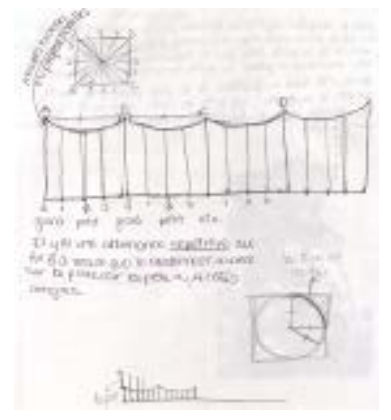

Figure 10. Agnes’s reconstruction including Frida's idea of using a circle.

\section{Final remarks}

This paper aimed to discuss two main results of our research: the usefulness of ACODESA, using a modelling process and developing a cultural milieu based on social interaction to help students shift from FRs related to the covariation between variables, to the IRs related to the graphical representation of functions. Furthermore, we studied how these representations evolved in the context of a PS.

In particular, we have discussed the emergence of FRs in the process of modelling through the use of PSs embedded in ACODESA, and their evolution in a learning setting based on a sociocultural post-Vygotskian perspective, addressing in this manner our first research question. From our point of view, the emergence of FRs seems to play a crucial role in the process of resolution of some PSs related to covariation between variables, as well as to the graphical representation of functions. We have exploited this in the construction of the set of activities following the ACODESA approach. In transmission teaching, teachers tend to present and to impose IRs immediately, without providing opportunities to the students' FRs to emerge. In our case, using ACODESA, immersed in Engeström's model (1999), we have created a rich learning environment, or sociocultural milieu, in a post-Vygotskian perspective (Radford, 1998). The essential components of this learning setting are mediating artefacts, semiotic mediation, FRs and their products, IRs, diversified thinking and goal-directed thinking. As a 
whole, this setting in the classroom can be considered as a micro society corresponding to the notion of a CSS. These theoretical elements have allowed us, as researchers, to observe and analyse the evolution of sense meaning (Bartolini Bussi, 2010; Falcade et al., 2007) constructed by the students throughout the different stages of the PS The Hiker.

In response to our second research question, ACODESA seems to have encouraged a cultural evolution in the students' representations, from the internal FRs and their productions, to the external IRs. Based upon the analysis of one team's work and the subsequent debate with the class, we have shown that the discussions among teammates and the debates among teams in the whole class setting seem to enable the students to share and to compare their representations, thus promoting a construction and evolution of a CSS. In fact, our data shows an evolution in the representations of the four members of the team, shifting from the productions associated to the FRs to the IRs. However, in a final stage, the students were also required to reflect upon the evolution and the articulation of their representations through an individual process of reconstruction of the classroom-based activities (e.g. Agnes's reconstruction in Figure 10). In our experimentation, we attempted to intertwine individual work and collaborative learning in a coherent process. In our experimentation we have also placed an emphasis on the crucial phase of reconstruction, which is very important when working in a sociocultural setting as it fosters sense meaning and avoids an ephemeral consensus among group members. We took into consideration research findings that illustrate how a consensus achieved in the classroom has been shown to be fragile (Thompson, 2002). Consequently, individual reconstruction is an important step to reinforce the stability of knowledge.

As we mentioned before, our block of activities was designed with the objective of achieving balance between fostering diversified thinking and goal-directed thinking. The students participating in our study seem to have developed the notion of covariation between variables and to have constructed an initial conception of function through the modelling process, as the evolution of their representations would indicate.

In accordance with the ACODESA approach, it is necessary to promote diversified thinking in the initial phase of a PS, while working in teams in a subsequent phase and participating in a debate regulated by the teacher will generate a goal-directed thinking process. Finally, the students must accept the responsibility of pursuing this process when revisiting the PS individually at home. The findings of our experimentation seem to support the efficacy of this articulation in fostering the evolution of representations and the stability of knowledge. We expect that the results reported here will encourage a discussion about the need of considering theoretical approaches to learning based upon sociocultural learning and a local theory of representations.

Taking into consideration the fact that an approach to learning based on the extended activity theory, using teaching methodologies such as ACODESA, may be perceived as being difficult to manage in a classroom setting, it is important to discuss the possible difficulties of implementation with the teacher more closely than with other research approaches. However, it is true that in the phase of debate, especially if there is the possibility of promoting a scientific debate (Alibert \& Thomas, 1991; Legrand, 2001), the teacher must be prepared to react accordingly when the students are ready to engage in an in-depth discussion. We 
believe that this issue requires more research in order to develop specific tools that will enable researchers to study this phase.

\section{Acknowledgements}

We thank the Conseil de Recherche en Sciences Humaines du Canada (No. 4102008-1836, CID 130 252). We also express our gratitude to the students and to the teacher Christian Morasse who participated in our research.

\section{References}

Alibert, D. \& Thomas, M. (1991). Research on mathematical proof. In D. Tall (Ed.), Advanced Mathematical Thinking (pp. 215-230). Kluwer Academic Publishers.

Artigue, M. (2002). L'intégration de calculatrices symboliques à l'enseignement secondaire : les leçons de quelques ingénieries didactiques. In D. Guin \& L. Trouche (Eds), Calculatrices Symboliques. Transformer un outil en un instrument du travail mathématique : un problème didactique (p. 277-349), Grenoble : La Pensée Sauvage.

Bartolini Bussi, M.G. (2010). Historical artefacts, semiotic mediation, and teaching proof. In G. Hanna, H.N. Jahnke \& H. Pulte (Eds.), Explanation and proof in mathematics: Philosophical and educational perspectives (pp. 151-168). New York: Springer.

Bloch, I. (2003). Teaching functions in a graphic milieu: What forms of knowledge enable students to conjecture and prove? Educational Studies in Mathematics, 52, 8-28.

Breidenbach, D., Dubinsky, E., Hawks, J. \& Nichols, D. (1992). Development of the process conception of function. Educational Studies in Mathematics, 23, 247-285.

Carlson M. (1998). A Cross-Sectional Investigation of the Development of the Function Concept. Research in Collegiate Mathematics Education, 7, 114162.

Carlson, M. (2002). Physical enactment: a powerful representational tool for understanding the nature of covarying relationships. In F. Hitt (Ed.), Representations and mathematics visualization (pp. 63-77), Special issue of PME-NA and Cinvestav-IPN.

Carlson, M., Oehrtman, M. \& Engelke, N. (2010). The precalculus concept assessment: A tool for assessing students' reasoning abilities and understanding. Cognition and Instruction, 28(2) 113-145.

Clement, J. (1989). The concept of variation and misconceptions in cartesian graphing. Focus on Learning Problems in Mathematics, 11(1-2), 77-87.

Davidson, N. (1998). L'apprentissage coopératif et en collaboration. Une tentative d'unification. In J. Thousand, R. Villa \& A. Nevin (Eds.), La créativité et l'apprentissage coopératif (p. 63-101), Les Éditions Logiques, Québec.

diSessa, A., Hammer, D., Sherin, B. \& Kolpakowski, T. (1991). Inventing Graphing: Meta-Representational Expertise in Children. Journal of Mathematical Behavior, 10, 117-160.

Duval, R. (1993). Registres de représentation sémiotique et fonctionnement cognitif de la pensée. Annales de Didactique et de Sciences Cognitives, 5, 37-65.

Duval, R. (1995). Sémiosis et pensée humaine: Registres sémiotiques et apprentissage intellectuels. Peter Lang, Suisse. 
Engeström, Y. (1987). Learning by expanding: An activity-theoretical approach to developmental research. Helsinki: Orienta-Konsultit.

Engeström, Y. (1999). Activity theory and individual and social transformation. In Y. Engeström, R. Miettinen \& R.-L. Punamäki (Eds.), Perspectives on activity theory (pp. 19-38). Cambridge University Press.

Falcade, R., Laborde, C. \& Mariotti, M.A. (2007). Approaching functions: Cabri tools as instruments of semiotic mediation. Educational Studies in Mathematics, 66, 317-333.

Font, V., Bolite, J. \& Acevedo, J. (2010). Metaphors in mathematics classrooms: analysing the dynamic process of teaching and learning of graph functions. Educational Studies in Mathematics, 75, 131-152.

Glaeser G. (1999). Une introduction à la didactique expérimentale des mathématiques. La Pensée Sauvage Éditions. France.

González-Martín, A.S., Hitt, F. \& Morasse, C. (2008). The introduction of the graphic representation of functions through the concept of covariation and spontaneous representations. A case study. In O. Figueras \& A. Sepúlveda (Eds.). Proceedings of the $32^{\text {nd }}$ Conference of the International Group for the Psychology of Mathematics Education and the $30^{\text {th }}$ PME-NA (Vol. 3, pp. 89-97). Morelia, Michoacán, Mexico: PME.

Hadamard, J. (1945/1975). Essai sur la psychologie de l'invention dans le domaine mathématique. Gauthier-Villars. Paris.

Harel, G. \& Dubinsky, E. (Eds.). (1992). The concept of function: Aspects of epistemology and pedagogy. MAA Notes, 25. Washington, DC.

Hitt F. (1994). Teachers' Difficulties with the Construction of Continuous and Discontinuous Functions. Focus on Learning Problems in Mathematics, 16(4), 10-20.

Hitt F. (2003). Le caractère fonctionnel des représentations. Annales de Didactique et des Sciences Cognitives, 8, 255-271.

Hitt, F. (2006). Students' functional representations and conceptions in the construction of mathematical concepts. An example: the concept of limit. Annales de Didactique et des Sciences Cognitives, 11, 253-268.

Hitt F. (2007). Utilisation de calculatrices symboliques dans le cadre d'une méthode d'apprentissage collaboratif, de débat scientifique et d'autoréflexion. In M. Baron, D. Guin \& L. Trouche (Eds.), Environnements informatisés et ressources numériques pour l'apprentissage. Conception et usages, regards croisés (pp. 65-88). Éditorial Hermès.

Hitt, F. \& Morasse, C. (2009). Développement du concept de covariation et de fonction en $3^{\text {ème }}$ secondaire dans un contexte de modélisation mathématique et de résolution de situations problèmes. Proceedings CIEAEM 61, Quaderni di Ricerca in Didattica (Matematica), Supplemento n. 2, 2009. http://math.unipa.it/ grim/cieaem/quaderno19_suppl_2.htm

Karsenty, R. (2003). What adults remember from their high school mathematics? The case of linear functions. Educational Studies in Mathematics, 51, 117144.

Legrand M. (2001). Scientific debate in mathematics courses. In D. Holton (Ed.), The teaching and learning of mathematics at university level: An ICMI Study (pp. 127-135). Dordretch : Kluwer Academic Publishers.

Leontiev, A. (1981). Sign and activity. In J.V. Wertsch (Ed.), The Concept of Activity Theory in Soviet Psychology (pp. 241-255). New York: M.E. Sharpe. 
Mesa, V. (2004). Characterizing practices associated with functions in middle school textbooks: An empirical approach. Educational Studies in Mathematics, 56, 225-286.

Ministère de l'Éducation, du Loisir et du Sport (MELS) (2007). Programme de Formation, Deuxième Cycle du Secondaire. http://www.mels.gouv.qc.ca/DGFJ/dp/menusec.htm

Monk, S. (1992). Students' understanding of a function given by a physical model. In E. Dubinsky \& G. Harel (Eds.), The concept of function. Aspects of epistemology and pedagogy (pp. 175-193). MAA Notes 25.

Nardi, B.A. (1997). Activity Theory and Human-Computer Interaction. In B.A. Nardi (Ed.), Context and Consciousness: Activity Theory and HumanComputer Interaction (pp. 4-8). MIT Press, London, England.

Passaro V. (2009). Obstacles à l'acquisition du concept de covariation et l'introduction de la représentation graphique en deuxième secondaire. Annales de Didactique et des Sciences Cognitives, 14, 61-77.

Presmeg, N. \& Balderas, P. (2002). Graduate Students' Visualization in Two Rate of Change Problems. In F. Hitt (Ed.), Representations and Mathematics Visualization (pp. 47-61), Special issue of PME-NA and Cinvestav-IPN.

Rabardel, P. (1995). Les hommes et les technologies, approche cognitive des instruments contemporains. Paris: Armand Colin.

Radford, L. (1998). On Culture and Mind, a post-Vygotskian Semiotic Perspective, with an Example from Greek Mathematical Thought. Paper presented at the $23^{\text {rd }}$ Annual Meeting of the Semiotic Society of America, Victoria College, University of Toronto, October 15-18, 1998.

Schwartz, B. \& Dreyfus, T. (1995). New actions upon old objects: A new ontological perspective on functions. Educational Studies in Mathematics, 29, 259-291.

Slavit, D. (1997). An alternate route to the reification of function. Educational Studies in Mathematics, 33, 259-281.

Slavit, D. \& Yeidel, J. (1999). Using web-based material in large-scale precalculus instruction. International Journal of Computers for Mathematical Learning, 4, 27-50.

Thompson P. (1994a). Images of rate and operational understanding of the fundamental theorem of calculus. Educational Studies in Mathematics, 26, 229-274.

Thompson P. (1994b). Students, functions, and the undergraduate mathematics curriculum. Research in Collegiate Mathematics Education, 1(4), 21-44.

Thompson P. (2002). Some remarks on conventions and representations. In F. Hitt (Ed.), Mathematics Visualisation and Representations (pp. 199-206). Mexico City: Psychology of Mathematics Education North American Chapter and Cinvestav-IPN.

Trigueros, M. \& Martínez-Planell, F. (2010). Geometrical representations in the learning of two-variable functions. Educational Studies in Mathematics, 73, 3-19.

Vygotsky, L. (1986). Thought and language. Cambridge MA: The MIT press. 